\title{
Anticancer effects of Ac-Phe-Lys-PABC-doxorubicin via mitochondria-centered apoptosis involving reactive oxidative stress and the ERK1/2 signaling pathway in MGC-803 cells
}

\author{
YAN-JUN ZHONG ${ }^{1}$, SHAO-PING LIU ${ }^{1}$, RAYMOND A. FIRESTONE ${ }^{2}$, YA-PING HONG ${ }^{2}$ and YAN LI ${ }^{1}$ \\ ${ }^{1}$ Department of Oncology, Zhongnan Hospital of Wuhan University, Hubei Key Laboratory of \\ Tumor Biological Behaviors and Hubei Cancer Clinical Study Center, Wuhan, Hubei 430071; \\ ${ }^{2}$ Nanjing Meihua Pharmaceuticals, Ltd., Nanjing 210009, P.R. China
}

Received March 19, 2013; Accepted July 10, 2013

DOI: 10.3892/or.2013.2629

\begin{abstract}
Ac-Phe-Lys-PABC-DOX (PDOX) is a smart doxorubicin (DOX) prodrug designed to decrease toxicities while maintaining the potent anticancer effects of DOX. The present study aimed to elucidate the molecular mechanisms of action of PDOX using MGC-803 gastric cancer cells as a model. The cells were treated with both PDOX and DOX, and cytotoxicities, cell cycle analysis, reactive oxygen species (ROS) generation, mitochondrial damage and ERK1/2 signaling pathway alterations were studied. Abundant cathepsin B expression was observed in the MGC-803 cells, and treatment with PDOX and DOX triggered dose-dependent cytotoxicity and resulted in a significant reduction in cell viability. $\mathrm{IC}_{50}$ of PDOX and DOX was 14.9 and $4.9 \mu \mathrm{M}$, respectively. Both PDOX and DOX significantly decreased p-ERK1/2, increased ROS generation, reduced mitochondrial membrane potential, caused mitochondrial swelling and arrested the cell cycle at the G2/S phase, and these effects were more pronounced for PDOX than for DOX. PDOX and DOX have different mechanisms of action, particularly the mitochondria-centered intrinsic apoptosis involving reactive oxidative stress and the ERK1/2 signaling pathway.
\end{abstract}

\section{Introduction}

Doxorubicin (DOX, Adriamycin), an anthracycline isolated from Streptomyces strains, is one of the most efficacious anticancer drugs for the treatment of hematological malig-

Correspondence to: Professor Yan Li, Department of Oncology, Zhongnan Hospital of Wuhan University, Hubei Key Laboratory of Tumor Biological Behaviors and Hubei Cancer Clinical Study Center, 169 Donghu Road, Wuhan, Hubei 430071, P.R. China

E-mail: liyansd2@163.com

Key words: gastric cancer, cathepsin B, doxorubicin, prodrugs, targeting therapy nancies and a broad range of solid tumors $(1,2)$. However, the clinical application of DOX has long been limited by its dose-dependent toxicities to the heart, kidney, liver and bone marrow. To reduce these side effects, significant efforts have been made to develop DOX-prodrugs, such as PK1 and PK2, which remain inactive in blood and normal tissues but release DOX at the tumor site (3), and which have entered phase II/III clinical studies $(4,5)$.

Cathepsin B (Cat B), a lysosomal cysteine protease in normal cells and tissues, is highly upregulated in malignant tumors and premalignant lesions at the mRNA, protein and activity levels (6). The active cleavage sites of Cat $\mathrm{B}$ cover a range of oligopeptides, including Arg-Arg, Ala-Leu, Phe-Arg, Phe-Lys, Ala-Phe-Lys, Gly-Leu-Phe-Gly, Gly-Phe-Leu-Gly and Ala-Leu-Ala-Leu (7-11). Therefore, several low- and high-molecular-weight DOX prodrugs through Cat B-cleavable oligopeptides, have been designed $(4,5,12)$ and have demonstrated rapid and nearly quantitative DOX release in the presence of Cat B.

Based on the characteristics of Cat B, we designed and developed a smart DOX prodrug, Ac-Phe-Lys-PABC-DOX (PDOX), in which a Cat B-specific dipeptide (Phe-Lys) is introduced, containing a self-immolative spacer para-aminobenzyloxycarbonyl (PABC) to increase the distance between the dipeptide and DOX (13-16), so that the dipeptide can be directly accessable to the Cat $\mathrm{B}^{\prime}$ active site. PDOX remains inactive and stable in blood circulation and normal tissues. When PDOX reaches Cat B-enriched areas such as tumor sites, the dipeptide Phe-Lys is cleaved by Cat B, exposing the PABC spacer that is hydrolyzed spontaneously, releasing free DOX.

An in vivo study in a nude mouse model of gastric cancer peritoneal carcinomatosis showed that, compared with free DOX, PDOX produced superior anti-metastasis effects in terms of the experimental peritoneal carcinomatosis index (ePCI) and body weight, and reduced toxicities to the liver, kidney and particularly the heart (16). However, the underlying mechanism remains unclear.

It has been reported that apoptosis plays a key role in the anticancer effects and toxicities of DOX (17), mainly via 
the mitochondria-centered intrinsic pathway $(18,19)$, which involves the release of cytochrome $c$ from the mitochondria $(20,21)$. DOX promotes the generation of reactive oxygen species (ROS) in various cell types $(22,23)$ and mitochondria are the major source of ROS production (24). The present study was aimed to investigate the in vitro mechanisms of action of PDOX with special focus on the mitochondria-centered intrinsic pathway.

\section{Materials and methods}

Drug preparation and cell culture. DOX (Pharmacia, Milan, Italy) and PDOX (synthesized by Y.-P.H.) were used. MGC-803 gastric cancer cells were cultured in $25 \mathrm{~cm}^{2}$ tissue culture flasks at $37^{\circ} \mathrm{C}$ in $5 \% \mathrm{CO}_{2}, 95 \%$ air and $100 \%$ humidity. Cells were grown in RPMI-1640 medium containing 10\% newborn calf serum and $1 \%$ penicillin and streptomycin. Throughout the study, the medium was replaced every 2 to 3 days. The cells were passaged when grown to $90 \%$ confluence.

Immunocytochemistry. Cells were transferred onto a coverslip in 6-well culture plates, grown for 2 days to reach $90 \%$ confluence and then fixed by ice-cold $4 \%$ paraformaldehyde for $30 \mathrm{~min}$. Immunocytochemistry for Cat B was then performed following a standard method (25). Briefly, cells were first blocked with $2 \%$ bovine serum albumin (BSA) at $37^{\circ} \mathrm{C}$ for $30 \mathrm{~min}$. Next, cells were incubated with a primary rabbit anti-human Cat B antibody (cat no. 3190-100, dilution 1:200; BioVision, Mountain View, CA, USA) at $4^{\circ} \mathrm{C}$ overnight. Cells were washed with Tris-buffered saline-Tween (TBST; $0.05 \%$ Tween, $0.1 \mathrm{M}$ Tris-base, $0.9 \% \mathrm{NaCl}, \mathrm{pH} 7.6) 3$ times and then incubated with a peroxidase-labled goat anti-rabbit $\mathrm{IgG}$ at $37^{\circ} \mathrm{C}$ for $30 \mathrm{~min}$. The antibody reaction products were visualized with diaminobenzidine (Dako, Denmark). The images were captured using an Olympus BX51 fluorescence microscope equipped with an Olympus Micro DP 72 camera.

Cell viability study by the 3-(4,5-dimethylthiazol-2-yl)-2,5-diphenyl-tetrazolium bromide (MTT) assay. Cells were passaged and $1 \times 10^{4}$ cells in $100 \mu \mathrm{l}$ medium were transferred into 96-well culture plates. After $24 \mathrm{~h}$, the MGC- 803 cells were treated with $0,0.86,1.72,3.44,6.88$ and $13.76 \mu \mathrm{M}$ of PDOX, or 0 , $0.86,1.72,3.44,6.88$ and $13.76 \mu \mathrm{M}$ DOX in medium for 24 , 48, 72 and $96 \mathrm{~h}$, respectively; then immediately incubated with $100 \mu 10.5 \mathrm{mg} / \mathrm{ml} \mathrm{MTT}$ at $37^{\circ} \mathrm{C}$ in $5 \% \mathrm{CO}_{2}, 95 \%$ air and $100 \%$ humidity for $4 \mathrm{~h}$. After medium removal, $150 \mu \mathrm{l}$ DMSO was added and incubated for $10 \mathrm{~min}$. $\mathrm{OD}_{560}$ was obtained by the ELISA (modulus microplate), and $\mathrm{IC}_{50}$ values were calculated.

Cell cycle analysis by flow cytometry. MGC-803 cells $\left(2 \times 10^{5}\right)$ in $2 \mathrm{ml}$ of medium were transferred into 6-well culture plates and cultured for $24 \mathrm{~h}$. The cells were treated with $0,14.9 \mu \mathrm{M}$ $\left(\mathrm{IC}_{50}\right.$ of PDOX treated for $48 \mathrm{~h}$ ), $4.9 \mu \mathrm{M}$ PDOX and 14.9 and $4.9 \mu \mathrm{M}\left(\mathrm{IC}_{50}\right.$ of DOX treated for $\left.48 \mathrm{~h}\right)$ DOX for $48 \mathrm{~h}$. The harvested cells were subjected to flow cytometry assay by Coulter $^{\circledR}$ DNA PREP ${ }^{\text {TM }}$ reagents kit according to the manufacturer's protocol. Briefly, cells were harvested, washed twice with phosphate-buffered saline (PBS) and re-suspended in serum-free medium, then $50 \mu$ l DNA PREP ${ }^{\mathrm{TM}}$ LPR buffer was added and incubated in a light-protected moist chamber for 20 min. Next, $500 \mu 1$ DNA PREP ${ }^{\mathrm{TM}}$ stain was added and incubated in the dark for $20 \mathrm{~min}$. Finally, cell cycle analysis was performed by flow cytometry (FC 500; Beckman Coulter, USA).

ROS generation and mitochondrial membrane potential $\left(\Delta \Psi_{m}\right)$ measurement. ROS generation was assayed using dichlorofluorescein diacetate (DCF-DA; Sigma, USA). The polar derivative from DCF-DA by intracellular esterases rapidly reacts with ROS to form a highly fluorescent compound (26). MGC-803 cells $\left(2 \times 10^{5}\right)$ in $2 \mathrm{ml}$ of medium were transferred into 6-well culture plates for $24 \mathrm{~h}$. The medium was replaced with serum-free medium the following day. Twelve hours later, cells were treated with $0,4.9$ and $14.9 \mu \mathrm{M}$ PDOX or 4.9 and $14.9 \mu \mathrm{M}$ DOX, respectively, for $48 \mathrm{~h}$. For ROS generation, cells were immediately incubated with $100 \mu \mathrm{M}$ DCF-DA at $37^{\circ} \mathrm{C}$ for $1 \mathrm{~h}$ in the dark. Images were captured using a laser confocal scanning microscope (Leica, Wetzlar, Germany) at $488 \mathrm{~nm}$ excitation and $525 \mathrm{~nm}$ emission.

For $\Delta \Psi \mathrm{m}$ assay, MGC-803 cells were treated in the same way as above and then immediately incubated with $100 \mathrm{nM}$ MitoTracker ${ }^{\circledR}$ Red CMXRos at $37^{\circ} \mathrm{C}$ for $30 \mathrm{~min}$ in the dark. Images were captured by a laser confocal scanning microscope at $579 \mathrm{~nm}$ excitation and $599 \mathrm{~nm}$ emission. For semi-quantitative analysis of ROS production and $\Delta \Psi \mathrm{m}$, total fluorescence intensity was analyzed with the LCS lite (Leica).

Mitochondrial morphology as determined by transmission electron microscopy. MGC-803 cells $\left(2 \times 10^{6}\right)$ in $8 \mathrm{ml}$ of medium were transferred into $10-\mathrm{cm}$ culture dishes. The cells were treated in the same way as above and harvested cells were initially fixed in $2.5 \%$ glutaraldehyde, then post-fixed in $1 \%$ osmic acid and embedded in epoxide resin. Ultrathin sections were cut with an ultramicrotome (LKB-V; Bromma, Sweden), stained with uranyl acetate and lead citrate, and examined using a transmission electron microscope (H-600; Hitachi, Japan) and photographed.

Western blotting. MGC- 803 cells $\left(2 \times 10^{5}\right)$ in $2 \mathrm{ml}$ of medium were transferred into 6 -well culture plates and treated in the same way as above. The harvested cells were homogenated, centrifuged at $12,000 \mathrm{xg}$ at $4^{\circ} \mathrm{C}$ for $30 \mathrm{~min}$, and the protein concentration in supernatants was determined using the BCA assay.

A total of $100 \mu \mathrm{g}$ proteins were separated by SDS-polyacrylamide gel electrophoresis (4\% stacking and $10 \%$ separating gels) and then transferred overnight onto PVDF membranes. The membranes were blocked with 5\% skimmed milk in $0.01 \mathrm{M}$ PBS containing $0.05 \%$ (v/v) Tween. Next, they were immunoblotted with rabbit anti-human p-ERK1/2 antibody (cat no. 4370, dilution 1:2,000), rabbit anti-human ERK1/2 (cat no. 4695, dilution 1:2,000; both from Cell Signaling Technology, Danvers, MA, USA), rabbit anti-human cytochrome $c$ (cat no. ab133504, dilution 1:1,000; Abcam, USA) for $2 \mathrm{~h}$. Blots were then incubated with a peroxidase-conjugated sheep anti-rabbit IgG (dilution 1:8,000; Santa Cruz Biotechnology, Inc., Santa Cruz, CA, USA) for $1 \mathrm{~h}$ and developed using chemiluminescent detection with a Supersignal West Pico Assay kit (Thermo, USA) and autoradiography film. 


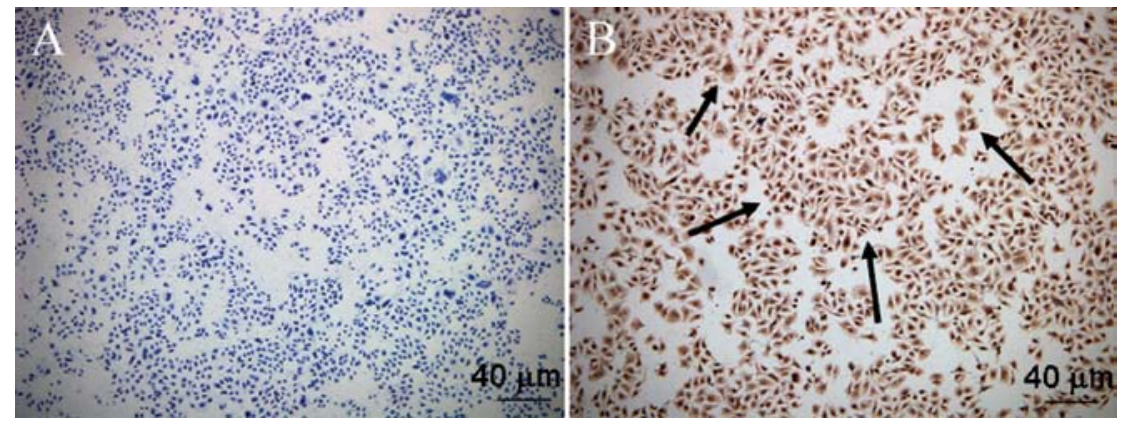

Figure 1. Expression of cathepsin B in MGC-803 cells as detected by immunocytochemistry. (A) Negative control, without Cat B primary antibody. (B) Cat B was highly expressed in the cytoplasm of MGC-803 cells.

$\mathbf{A}$

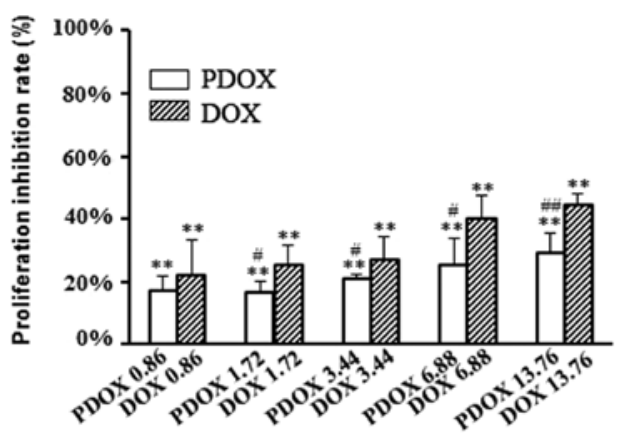

C

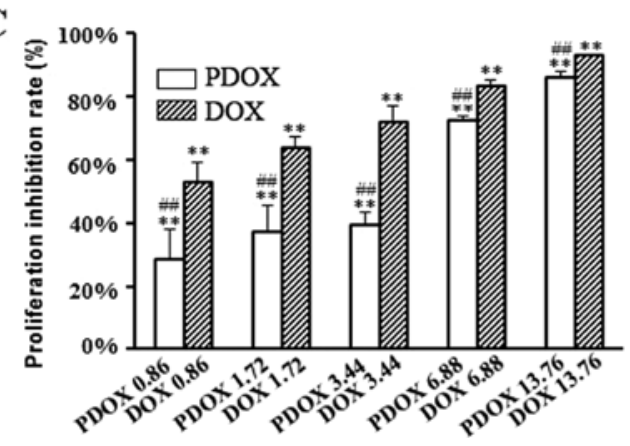

B

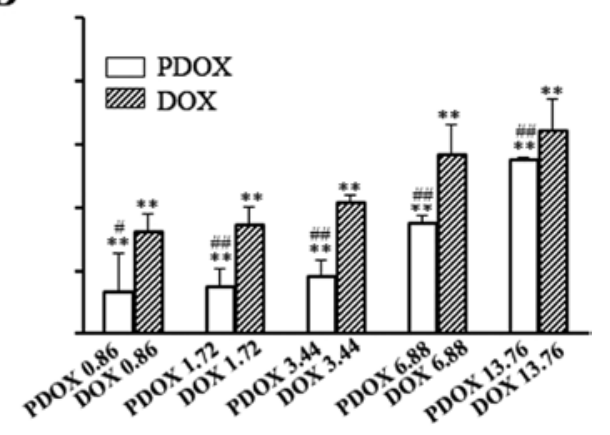

D

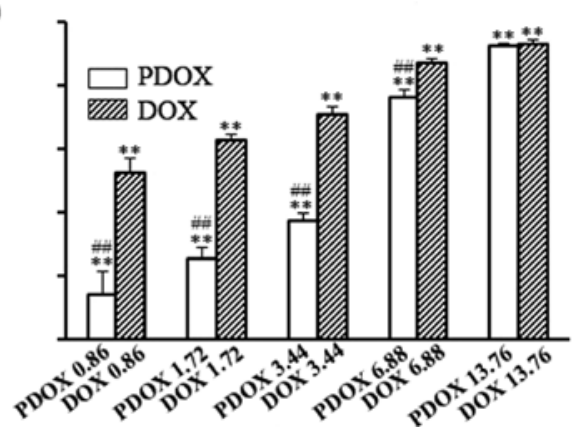

Figure 2. Effects of doxorubicin (DOX) and Ac-Phe-Lys-PABC-DOX (PDOX) on MGC-803 cell viability following treatement for (A) 24, (B) 48, (C) 72 and (D) $96 \mathrm{~h} .{ }^{*} \mathrm{P}<0.05$ compared with control; ${ }^{* *} \mathrm{P}<0.01$ compared with control; ${ }^{* * *} \mathrm{P}<0.001$ compared with control; ${ }^{*} \mathrm{P}<0.05$ compared with an equal molarity of DOX; ${ }^{\# \#} \mathrm{P}<0.01$ compared with an equal molarity of DOX; ${ }^{\# \#} \mathrm{P}<0.001$ compared with an equal molarity of DOX.

\section{Results}

Cat B expression in MGC-803 cells. As shown in Fig. 1, immunocytochemical analysis revealed abundant Cat B expression in the cytoplasm of the MGC-803 cells.

Cytotoxic effects of DOX and PDOX on MGC-803 cells. To investigate the cytotoxic effects of DOX and PDOX, MGC-803 cells were treated with the indicated concentrations of DOX and PDOX for 24, 48, 72 and $96 \mathrm{~h}$, respectively. As confirmed by the MTT assay, DOX and PDOX triggered dose-dependent cytotoxicity and resulted in a significant reduction in cell viability (Fig. 2). At $48 \mathrm{~h}$, the rates of proliferation inhibition following treatment with $0.86,1.72,3.44,6.88$ and $13.76 \mu \mathrm{M}$ of PDOX were $13.17 \pm 12.12,15.10 \pm 5.46,18.33 \pm 4.85,34.99 \pm 2.27$ and $54.86 \pm 0.93 \%$, respectively; and following treatment with the same concentrations of DOX were $32.30 \pm 5.47,34.39 \pm 5.81$, $41.50 \pm 2.58,52.35 \pm 9.25$ and $59.97 \pm 10.29 \%$, respectively
(Fig 2B). At $48 \mathrm{~h}$ of treatment, the $\mathrm{IC}_{50}$ concentration of PDOX $(14.9 \mu \mathrm{M})$ was 3.04 times that of DOX $(4.9 \mu \mathrm{M})$.

Effects of DOX and PDOX on the cell cycle distribution of $M G C-803$ cells. To study the effects of DOX and PDOX on the cell cycle, MGC-803 cells were treated with 4.9 and $14.9 \mu \mathrm{M}$ PDOX or 4.9 and $14.9 \mu \mathrm{M}$ DOX for $48 \mathrm{~h}$, respectively. The percentages of cells at phases G1, G2 and S were 56.1, 18.7 and $25.5 \%$ in the control group; 37.0, 40.2 and $22.8 \%$ in the $4.9 \mu \mathrm{M}$ DOX group; $29.2,46.6$ and $24.2 \%$ in the $4.9 \mu \mathrm{M}$ PDOX group; 33.6, 41.7 and $24.7 \%$ in the $14.9 \mu \mathrm{M}$ DOX group; and 14.4, 55.3 and $30.3 \%$ in the $14.9 \mu \mathrm{M}$ PDOX group (Fig. 3). These results suggest that both PDOX and DOX arrested the cell cycle at the $\mathrm{G} 2 / \mathrm{S}$ phase. Moreover, $\mathrm{PDOX}$ at $\mathrm{IC}_{50}$ arrested more cells at the $\mathrm{G} 2 / \mathrm{S}$ phase compared with DOX at $\mathrm{IC}_{50}$.

Effects of DOX and PDOX on ROS generation of MGC-803 cells. ROS generation of MGC-803 cells was significantly 


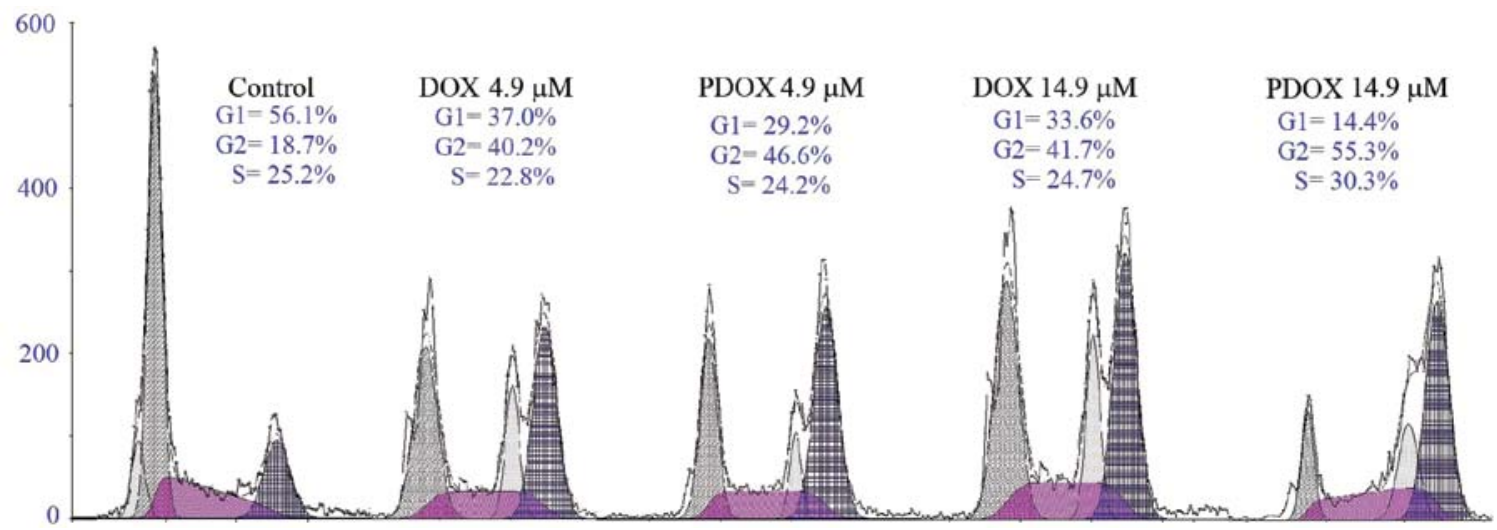

Figure 3. Effect of doxorubicin (DOX) and Ac-Phe-Lys-PABC-DOX (PDOX) on the cell cycle distribution of MGC-803 cells was determined by flow cytometry. Both PDOX and DOX arrested the cell cycle at the $\mathrm{G} 2 / \mathrm{S}$ phase. Compared with DOX at $\mathrm{IC}_{50}, \mathrm{PDOX}$ at $\mathrm{IC}_{50}$ arrested a higher percentage of cells at the $\mathrm{G} 2 / \mathrm{S}$ phase.
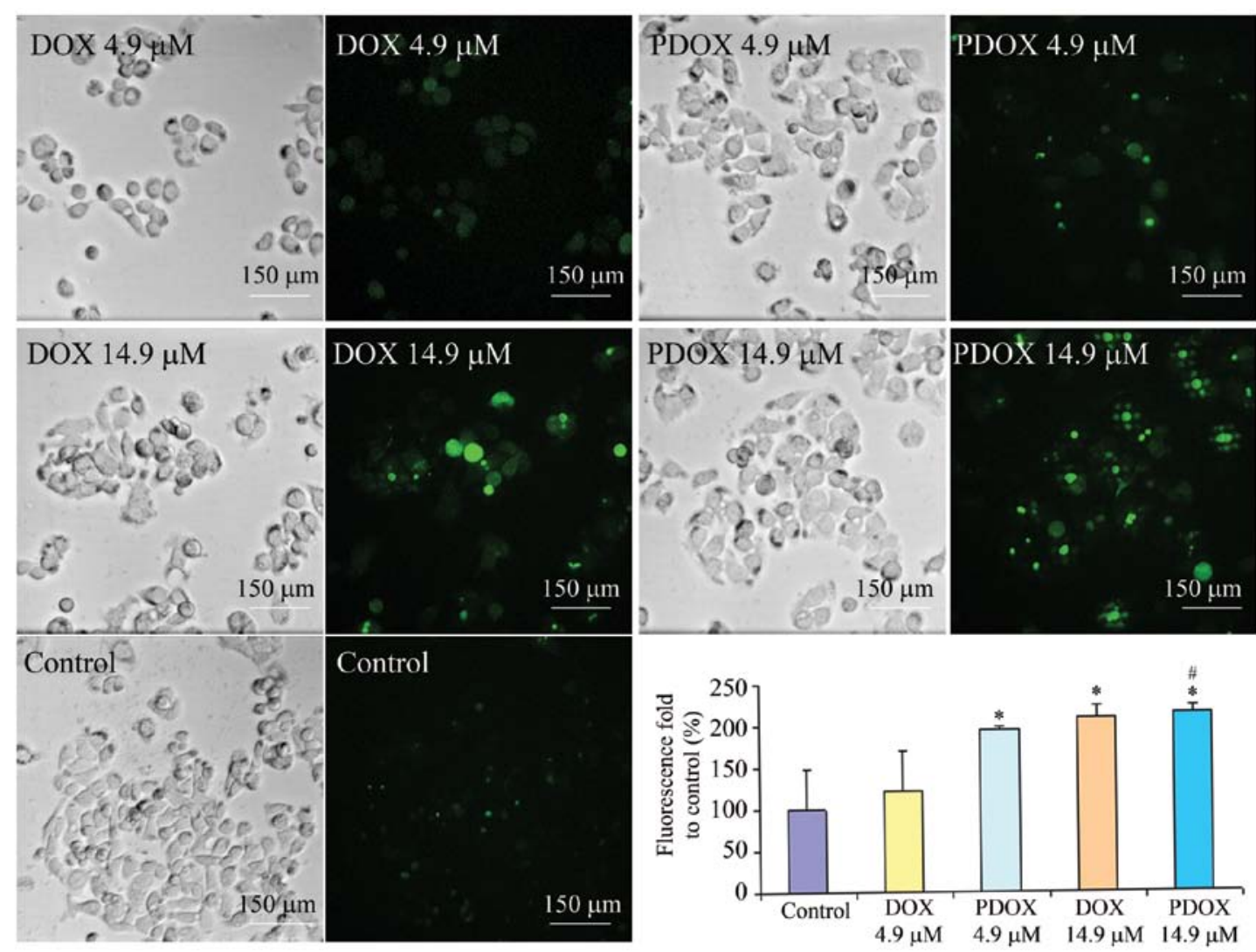

Figure 4. Doxorubicin (DOX) and Ac-Phe-Lys-PABC-DOX (PDOX) significantly induced reactive oxygen species generation. ${ }^{*} \mathrm{P}<0.05$ compared with control; ${ }^{\#} \mathrm{P}<0.05$ compared with DOX at $\mathrm{IC}_{50}$.

increased by PDOX when compared with that by DOX (Fig. 4). Compared with the control, ROS levels were increased by 1.20 -fold $(\mathrm{P}>0.05), 1.95$-fold $(\mathrm{P}<0.05), 2.09$-fold $(\mathrm{P}<0.05)$ and 2.15-fold $(\mathrm{P}<0.05)$ following treatment of $4.9 \mu \mathrm{M}$ DOX or PDOX, $14.9 \mu \mathrm{M}$ DOX or PDOX, respectively. Meanwhile, compared with DOX at $\mathrm{IC}_{50}, \mathrm{PDOX}$ at $\mathrm{IC}_{50}$ significantly increased ROS generation (1.53-fold, $\mathrm{P}<0.05)$.

Effects of DOX and PDOX on the mitochondria in MGC-803 cells. $\triangle \Psi \mathrm{m}$ of MGC-803 cells was significantly decreased following treatment with both DOX and PDOX (Fig. 5A). Compared with the control, fluorescence intensity was increased by 1.04-fold $(\mathrm{P}<0.05), 1.07$-fold $(\mathrm{P}<0.001), 1.08$-fold $(\mathrm{P}<0.01)$ and 1.10 -fold $(\mathrm{P}<0.001)$ after treatment with $4.9 \mu \mathrm{M}$ DOX or PDOX and $14.9 \mu \mathrm{M}$ DOX or PDOX, respectively. Meanwhile, compared with DOX at $\mathrm{IC}_{50}, \mathrm{PDOX}$ at $\mathrm{IC}_{50}$ significantly increased fluorescence values $(1.53$-fold, $\mathrm{P}<0.01)$.

Results of transmission electron microscopy revealed that PDOX and DOX induced mitochondrial swelling, particularly in cells treated with PDOX at $\mathrm{IC}_{50}$ (Fig. 5B).

Effects of DOX and PDOX on ERK1/2 phosphorylation and cytoplasmic cytochrome c release in MGC- 803 cells. Phosphorylation of ERK1/2 was significantly reduced by both 
A
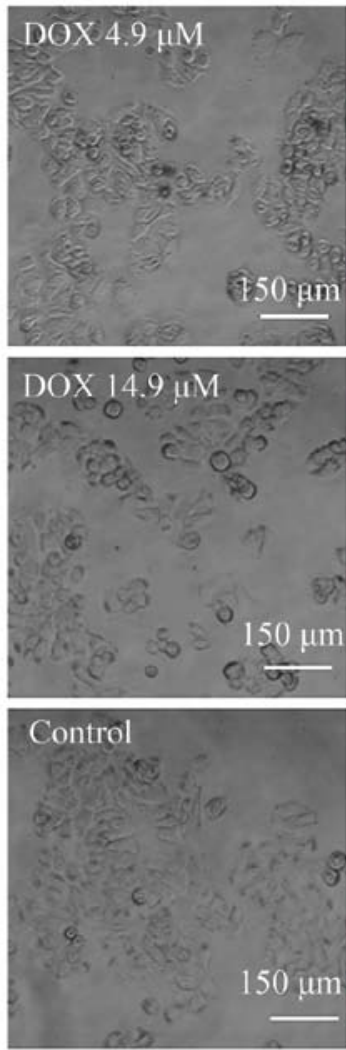

B

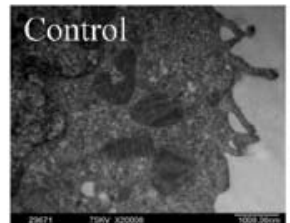

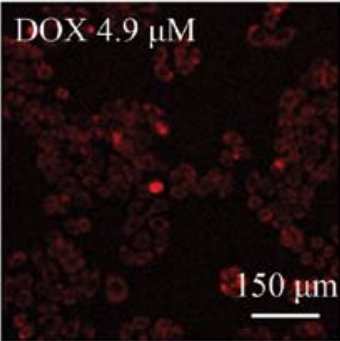

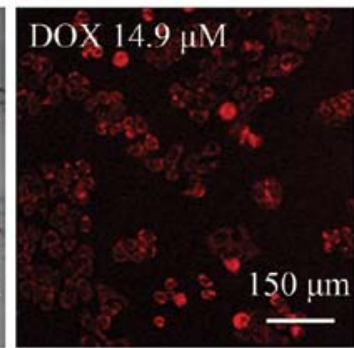

\section{Control}
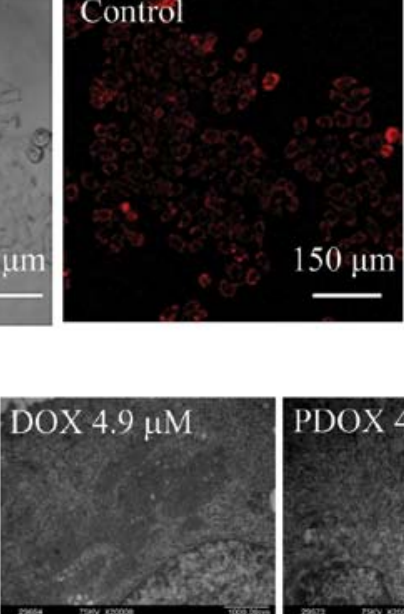
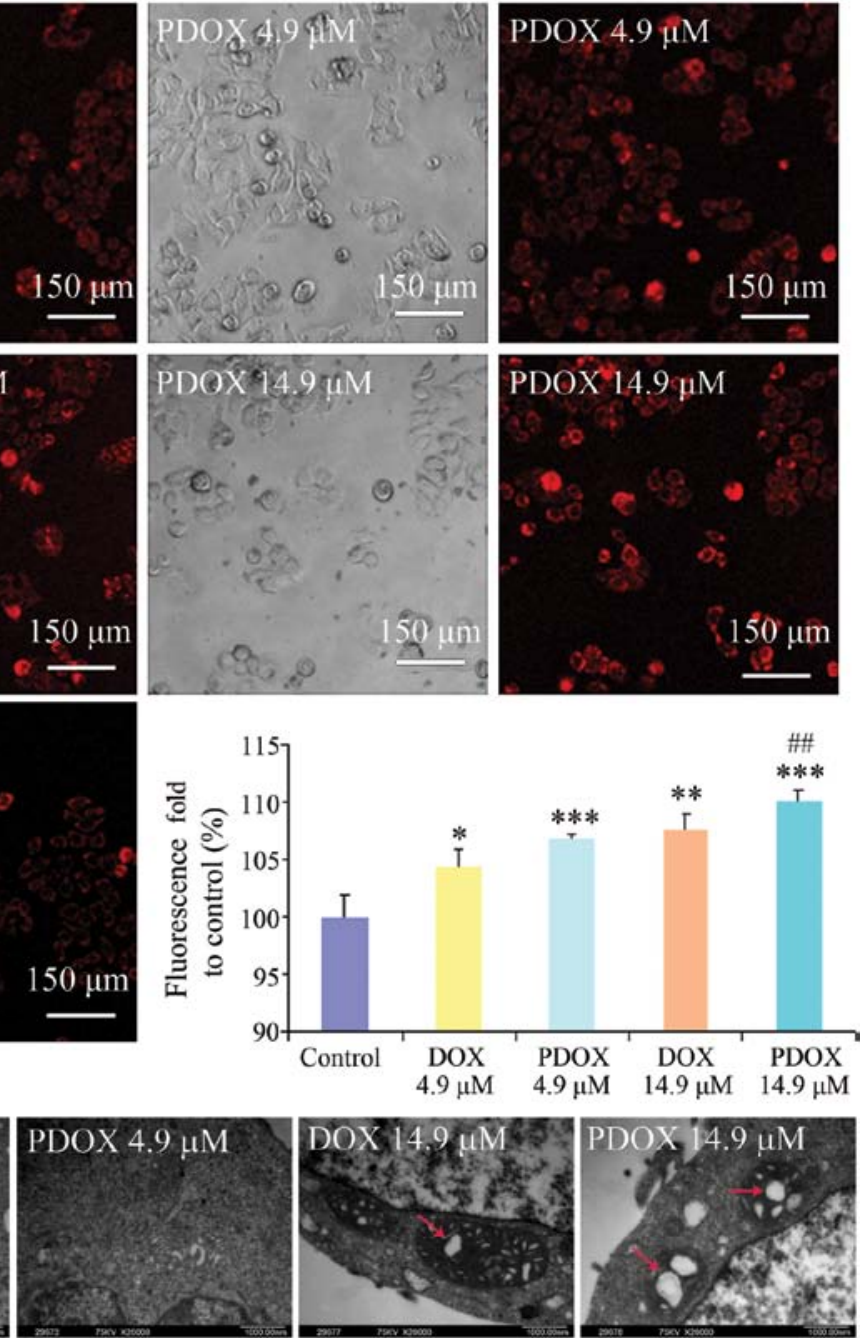

Figure 5. Effects of Ac-Phe-Lys-PABC-DOX (PDOX) and doxorubicin (DOX) on mitochondria. (A) PDOX and DOX significantly reduced mitochondrial transmembrane potential. (B) PDOX and DOX induced mitochondrial swelling (red arrows). " $\mathrm{P}<0.05$ compared with control; ** $\mathrm{P}<0.01$ compared with control; ${ }^{* * *} \mathrm{P}<0.001$ compared with control; ${ }^{\# /} \mathrm{P}<0.01$ compared with DOX at $\mathrm{IC}_{50}$.

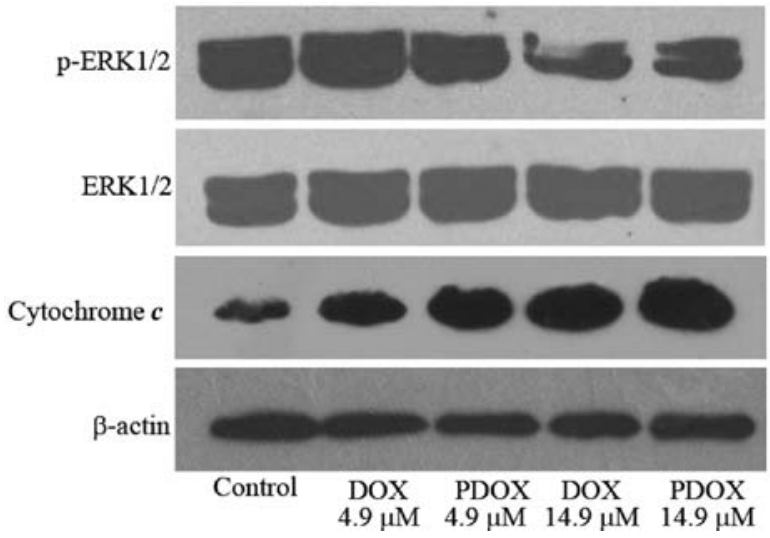

Figure 6. Effects of Ac-Phe-Lys-PABC-DOX (PDOX) and doxorubicin (DOX) on p-ERK1/2, ERK1/2 and cytoplasmic cytochrome $c$ expression as detected using western blotting.

PDOX and DOX treatments, and the effect of PDOX was much more marked. Similarly, cytoplasmic cytochrome $c$ was increased following both PDOX and DOX treatments, and the effect of PDOX was more obvious (Fig. 6).

\section{Discussion}

DOX is one of the most commonly used chemotherapeutic drugs with proven efficacy, but is associated with serious side effects. To resolve this issue, the 'smart' DOX-prodrug PDOX was designed with increased in vivo anti-metastasis effects and reduced toxicities in gastric cancer peritoneal carcinomatosis (16).

The present study aimed to elucidate the molecular mechanisms of action of PDOX using MGC-803 cells as a model, since immunocytochemical analysis demonstrated that this cell line is rich in Cat B. Our results showed that: i) the direct cytotoxicity of PDOX on cancer cells did not exceed that of DOX since the $\mathrm{IC}_{50}$ of PDOX was significantly higher than that of DOX; ii) PDOX induced a greater degree of mitochondria-centered intrinsic apoptosis than DOX, since more cytochrome $c$ was released from the mitochondria into the cytoplasm following PDOX treatment; iii) PDOX promoted more ROS production and significantly inhibited p-ERK1/2 to a greater degree than DOX. Therefore, treatment with both PDOX and DOX caused mitochondrial swelling and arrested the cell cycle at the G2/S phase; moreover, the effects of PDOX 
on mitochondria and the cell cycle were more marked than DOX.

Previous studies found that the two N-(2-hydroxypropyl) methacrylamide copolymer-bound DOX-prodrugs (PK1 and HYD) and free DOX greatly differ in regards to their antiproliferative effect and cell death signals in EL-4 cancer cells; treatment with free DOX greatly increased p38 phosphorylation, while PK1 increased it slightly; PK1 also significantly increased ERK phosphorylation, while the free DOX slightly decreased it (27). Based on our study and on the results from the PK1 study, we conclude that antitumor mechanisms of action of a prodrug may be different from the original drug itself. Molecular modifications could bring new active groups, structural changes, drug metabolic alterations, which together may account for the different mechanisms of action from free DOX. This also suggests that the prodrugs may have a different antitumor spectrum. Therefore, more studies are needed to investigate the molecular mechanisms of action and the antitumor spectrum.

In conclusion, the present study found that PDOX has different mechanisms of action, particularly the mitochondria-centered intrinsic pathway involving reactive oxidative stress and the ERK1/2 signaling pathway. The new knowledge gained from this study may aid in the development of PDOX as a 'smart' molecular targeting drug against cancer metastasis.

\section{Acknowledgements}

The present study was supported by the State Key Research Project on Infectious Diseases (2012ZX10002012-012) and the National Natural Science Foundation of China (no. 81171396) and National University Students Innovation Training Project of China (101048639).

\section{References}

1. Gianni L, Grasselli G, Cresta S, Locatelli A, Viganò L and Minotti G: Anthracyclines. Cancer Chemother Biol Response Modif 21: 29-40, 2003.

2. Abu Ajaj K, Graeser R, Fichtner I and Kratz F: In vitro and in vivo study of an albumin-binding prodrug of doxorubicin that is cleaved by cathepsin B. Cancer Chemother Pharmacol 64: 413-418, 2009.

3. Kratz F, Warnecke A, Schmid B, Chung DE and Gitzel M: Prodrugs of anthracyclines in cancer chemotherapy. Curr Med Chem 13: 477-523, 2006.

4. Seymour LW, Ferry DR, Kerr DJ, Rea D, Whitlock M, Poyner R, et al: Phase II studies of polymer-doxorubicin (PK1, FCE28068) in the treatment of breast, lung and colorectal cancer. Int J Oncol 34: 1629-1636, 2009.

5. Seymour LW, Ferry DR, Anderson D, Hesslewood S, Julyan PJ, Poyner R, et al: Hepatic drug targeting: Phase I evaluation of polymer-bound doxorubicin. J Clin Oncol 20: 1668-1676, 2002.

6. Podgorski I and Sloane BF: Cathepsin B and its role(s) in cancer progression. Biochem Soc Symp 70: 263-276, 2003.

7. Calderón M, Graeser R, Kratz F and Haag R: Development of enzymatically cleavable prodrugs derived from dendritic polyglycerol. Bioorg Med Chem Lett 19: 3725-3728, 2009.

8. Kovár M, Strohalm J, Etrych T, Ulbrich K and Ríhová B: Star structure of antibody-targeted HPMA copolymer-bound doxorubicin: a novel type of polymeric conjugate for targeted drug delivery with potent antitumor effect. Bioconjug Chem 13: 206-215, 2002
9. Thanou M and Duncan R: Polymer-protein and polymer-drug conjugates in cancer therapy. Curr Opin Investig Drugs 4: 701-709, 2003.

10. Mai J, Waisman DM and Sloane BF: Cell surface complex of cathepsin B/annexin II tetramer in malignant progression. Biochim Biophys Acta 1477: 215-230, 2000.

11. Kratz F, Müller IA, Ryppa C and Warnecke A: Prodrug strategies in anticancer chemotherapy. Chem Med Chem 3: 20-53, 2008.

12. Vasey PA, Kaye SB, Morrison R, Twelves C, Wilson P, Duncan R, et al: Phase I clinical and pharmacokinetic study of PK1 (N-(2-hydroxypropyl)methacrylamide copolymer doxorubicin): first member of a new class of chemotherapeutic agents-drug-polymer conjugates. Cancer Research Campaign Phase I/II Committee. Clin Cancer Res 5: 83-94, 1999.

13. Dubowchik GM and Firestone RA: Cathepsin B-sensitive dipeptide prodrugs. 1. A model study of structural requirements for efficient release of doxorubicin. Bioorg Med Chem Lett 8: 3341-3346, 1998.

14. Dubowchik GM, Firestone RA, Padilla L, Willner D, Hofstead SJ, Mosure K, et al: Cathepsin B-labile dipeptide linkers for lysosomal release of doxorubicin from internalizing immunoconjugates: model studies of enzymatic drug release and antigen-specific in vitro anticancer activity. Bioconjug Chem 13: 855-869, 2002.

15. Dubowchik GM, Mosure K, Knipe JO and Firestone RA: Cathepsin B-sensitive dipeptide prodrugs. 2. Models of anticancer drugs paclitaxel (Taxol), mitomycin $\mathrm{C}$ and doxorubicin. Bioorg Med Chem Lett 8: 3347-3352, 1998.

16. Shao LH, Liu SP, Hou JX, Zhang YH, Peng CW, Zhong YJ, et al: Cathepsin B cleavable novel prodrug Ac-Phe-Lys-PABC-ADM enhances efficacy at reduced toxicity in treating gastric cancer peritoneal carcinomatosis: an experimental study. Cancer 118: 2986-2996, 2012

17. Liu LL, Li QX, Xia L, Li J and Shao L: Differential effects of dihydropyridine calcium antagonists on doxorubicin-induced nephrotoxicity in rats. Toxicology 231: 81-90, 2007.

18. Hancock JT, Desikan R and Neill SJ: Role of reactive oxygen species in cell signalling pathways. Biochem Soc Trans 29: 345-350, 2001.

19. Fruehauf JP and Meyskens FL Jr: Reactive oxygen species: a breath of life or death? Clin Cancer Res 13: 789-794, 2007.

20. Korsmeyer SJ, Yin XM, Oltvai ZN, Veis-Novack DJ and Linette GP: Reactive oxygen species and the regulation of cell death by the Bcl-2 gene family. Biochim Biophys Acta 1271: 63-66, 1995.

21. Gupta S: Molecular signaling in death receptor and mitochondrial pathways of apoptosis (Review). Int J Oncol 22: 15-20, 2003.

22. Tsang WP, Chau SP, Kong SK, Fung KP and Kwok TT: Reactive oxygen species mediate doxorubicin induced p53-independent apoptosis. Life Sci 73: 2047-2058, 2003.

23. Wang S, Konorev EA, Kotamraju S, Joseph J, Kalivendi S and Kalyanaraman B: Doxorubicin induces apoptosis in normal and tumor cells via distinctly different mechanisms. intermediacy of $\mathrm{H}(2) \mathrm{O}(2)-$ and p53-dependent pathways. J Biol Chem 279: 25535-25543, 2004.

24. Moungjaroen J, Nimmannit U, Callery PS, Wang L, Azad N, Lipipun V, et al: Reactive oxygen species mediate caspase activation and apoptosis induced by lipoic acid in human lung epithelial cancer cells through Bcl-2 down-regulation. J Pharmacol Exp Ther 319: 1062-1069, 2006.

25. Peng CW, Liu XL, Chen C, Liu X, Yang XQ, Pang DW, et al: Patterns of cancer invasion revealed by QDs-based quantitative multiplexed imaging of tumor microenvironment. Biomaterials 32: 2907-2917, 2011.

26. Shinomol GK, Muralidhara: Effect of Centella asiatica leaf powder on oxidative markers in brain regions of prepubertal mice in vivo and its in vitro efficacy to ameliorate 3-NPA-induced oxidative stress in mitochondria. Phytomedicine 15: 971-984, 2008.

27. Kovár L, Strohalm J, Chytil P, Mrkvan T, Kovár M, Hovorka O, et al: The same drug but a different mechanism of action: comparison of free doxorubicin with two different $\mathrm{N}$-(2-hydroxypropyl) methacrylamide copolymer-bound doxorubicin conjugates in EL-4 cancer cell line. Bioconjug Chem 18: 894-902, 2007. 